\title{
Hypothalamic centres involved in the control of gonadotrophin secretion
}

\author{
E. Domański, F. Przekop and Jolanta Polkowska \\ Institute of Animal Physiology and Nutrition, 05-110 Jablonna near Warsaw, Poland
}

In this paper the problem of the hypothalamic centres involved in the control of gonadotrophin secretion will be presented, based on investigations performed on rats and sheep. The data obtained for the rat were chosen because the control of gonadotrophin secretion in this animal is best known, and therefore this animal may be considered as a model to be compared with the others. On the other hand, the sheep, retaining seasonality of reproductive processes, represents the most natural model of reproduction among farm animals.

According to earlier concepts, the release of gonadotrophins from the pituitary gland was supposed to be under hypothalamic control displayed at two levels: the medial basal hypothalamus (MBH) was claimed to produce gonadotrophic releasing hormones (Gn-RHs) and mediate the tonic secretion of gonadotrophins, whereas the preoptic anterior hypothalamic area (PAHA) was thought to initiate phasic, preovulatory release of gonadotrophins and was considered to be the 'regulatory centre' of this process. Evidence for this hypothesis emerged mainly from investigations carried out on rats (Flerkó, 1970; Barraclough, 1973) and also partly on sheep (Przekop \& Domański, 1970). The results obtained from other species were not in accordance with this hypothesis.

On the basis of our present knowledge it may be said that the hypothesis of hypothalamic regulation at two levels does not agree with recent findings concerning the site of LH-RH production in rats and sheep and a so-called 'regulatory' centre in rats.

\section{The hypothalamic sites of LH-RH localization}

The initial immunocytological studies carried out on the rat demonstrated LH-RH-immunoreactive material only in nerve fibres and in presumed sites of terminal distribution such as the median eminence and organum vasculosum of the lamina terminalis (OVLT). There was a general failure to visualize LH-RH in neurone perikarya. On the other hand, in some other species, e.g. men, monkeys, cats and dogs, this material was demonstrated in the perikarya of the rostral hypothalamus and the arcuate nucleus (ARC). During recent years the view of the localization and distribution of immunoreactive LH-RH material in the rat has changed. Sétáló, Vigh, Schally, Arimura \& Flerkó (1976) in Nembutal-injected or frontally deafferentated rats found nerve cell bodies containing LH-RH in the suprachiasmatic and prechiasmatic areas.

This finding suggests that some of the LH-RH-producing nerve cells situated in the suprachiasmatic area send their axons into the $\mathrm{MBH}$, and the reason for the failure to demonstrate LH-RH immunoreactive material in these cells would be the rapid transport of this hormone from the cell bodies, so that its concentration there remains too low for immunocytochemical detection.

It is now generally accepted that two hypothalamic regions in the rat contain abundant LHRH immunoreactive material, i.e. neurones in retrochiasmatic-arcuate region and those in the 
preoptic-septal region. During the oestrous cycle of the rat the most abundant material is present in the axons and nerve endings of the zona palisadica of the median eminence (ME) in early pro-oestrus; this material disappears almost completely during late pro-oestrus (Polkowska \& Jutisz, 1979). The distribution pattern of positive nerve fibres in the sheep hypothalamus resembles that observed in the rat. In our studies, the distribution of LH-RH immunoreactive material was followed in ovariectomized and cyclic ewes. On Day 16 of the oestrous cycle (just before ovulation) abundant material was observed in a wide segment of the zona palisadica in the ME. By $24 \mathrm{~h}$ after ovulation the immunoreactive droplets were almost absent and only slightly stained in the rostral and central parts of the ME (Pl. 1, Figs 1 and 2). The material remained only in the caudal part of the ME. The concentration of LH-RH material in the OVLT was not very high and did not vary throughout the oestrous cycle.

In ovariectomized ewes we found some positive LH-RH fibres in the anterior part of the hypothalamus (in the nucleus hypothalamicus anterior) running parallel to the 3rd ventricle, just above the nucleus suprachiasmaticus. Recent observations on rostrally deafferentated sheep confirmed the presence of LH-RH material in this part of the hypothalamus.

However, the data presented do not permit precise determination of the main site of LH-RH production in rats and sheep. In spite of our insufficient knowledge concerning the site of synthesis of the hormone, all the data indicate that the axons situated in the area of the ventral arcuate nuclei, and especially in the area of the zona palisadica of the ME, contain the highest quantities of LH-RH and this area may be considered as accumulating this hormone before release and transmission to the pituitary gland.

\section{Hypothalamic centres regulating the release of gonadotrophins}

Two different modes of gonadotrophic hormone secretion occur during the oestrous cycle in spontaneously ovulating animals; a so-called tonic secretion during meta- and dioestrus and a phasic secretion occurring before ovulation.

Tonic secretion of $\mathrm{LH}$ is characterized by continuous pulsatile surges of the hormone at a very low rate. The $\mathrm{MBH}-\mathrm{ARC}$ is claimed, as mentioned above, to be involved in this process. The involvement of the $\mathrm{MBH}$ has been proved by the finding that $\mathrm{LH}$ release is maintained at a very low rate after the anterior deafferentation of this hypothalamic region. This low rate of gonadotrophin release is sufficient to maintain the ovaries and prevent their atrophy.

Quite different hypothalamic functional organization is involved in the phasic preovulatory release of gonadotrophins. According to the earlier concepts mentioned above, the PAHA in the rat was considered to be the 'regulatory centre' of this process. However, this view has undergone some changes because Clemens, Smalstig \& Sawyer (1976) demonstrated that the discrete lesions of the preoptic area failed to eliminate ovulation in female rats. This finding agrees with the observations of Hayashi, Mennin \& Gorski (1974), who reported maintenance of ovulation in rats after deafferentation of the medial preoptic area (MPOA) if the cuts were made rostrally to the suprachiasmatic nuclei $(\mathrm{SCN})$ and these nuclei were not injured. Injury to the SCN led to the elimination of the phasic release of LH in intact (Brown-Grant \& Raisman, 1977) and ovariectomized (Gray, Söderstein, Tallentire \& Davidson, 1978) rats, as measured by the positive feedback response to oestradiol or the response to mating. Gray et al. (1978) are of the opinion that damage to portions of preoptic area may produce deficiencies in phasic LH release of varied degree, resulting not in complete loss of phasic release but rather in a reduction in responsiveness of the phasic component. The role of the preoptic area may be contributory in contrast to the obligatory role of the SCN. The SCN are located at the nodal point in a complex network of hypothalamic connections and because of this arrangement and the direct connections with afferent fibres from the retina they are considered to be involved in the 
regulation of a variety of circadian rhythms, apparently functioning as a central 'biological clock' (Stephan \& Zucker, 1972; Stetson \& Watson-Whitmyre, 1976).

Earlier and more recent investigations performed in our laboratory on the role of the PAHA in the control of gonadotrophin secretion have shown that the function of these neural components in sheep is different from that shown for rats. Damage to the MPOA (Przekop \& Domański, 1970) or cuts of the hypothalamus rostrally to the SCN (Przekop, 1978; Text-fig. 1), did not disturb oestrous cycles or ovulations during the breeding season but did change the duration of the season because the cycles continued into the normally quiescent non-breeding season.

In an attempt to identify critical structures in the PAHA, destruction of which leads to disturbances of the seasonality of oestrous cycles, we examined the effects of lesions of the suprachiasmatic nuclei and the surrounding area on the occurrence of oestrous cycles in ewes throughout the whole year. The results of these experiments are briefly presented in Table 1.

Table 1. Plasma LH concentrations and the incidence of oestrous cycles in ewes with lesions of the suprachiasmatic nuclei (SCN)

\begin{tabular}{|c|c|c|c|c|c|}
\hline \multirow{3}{*}{$\begin{array}{c}\text { No. of } \\
\text { animals }\end{array}$} & \multirow{3}{*}{ Location of lesion } & \multirow{2}{*}{\multicolumn{2}{|c|}{ Incidence of oestrous cycles }} & \multicolumn{2}{|c|}{ 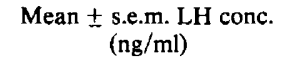 } \\
\hline & & & & & Preovulatory \\
\hline & & Breeding season & Anoestrus & Basal & peak \\
\hline 6 & $\begin{array}{l}\text { Almost entire SCN (cross- } \\
\text { hatched area-Text-figs } 2 \\
\text { and 3a) }\end{array}$ & Regular periodicity & $\begin{array}{l}\text { Extended with regular } \\
\text { intervals for 3-5 } \\
\text { months }\end{array}$ & $1.8 \pm 0.25$ & $88.6 \pm 7.42$ \\
\hline 4 & $\begin{array}{l}\text { Caudal SCN (diagonally } \\
\text { hatched area-Text-fig. 2) }\end{array}$ & Irregular intervals & $\begin{array}{l}\text { Extended with irregular } \\
\text { intervals for 3-5 } \\
\text { months }\end{array}$ & $1.8 \pm 0.15$ & $91 \cdot 3 \pm 4 \cdot 40$ \\
\hline 3 & $\begin{array}{l}\text { AHA above SCN (vertically } \\
\text { hatched area-Text-figs } \\
2 \text { and } 3 \mathrm{~b} \text { ) }\end{array}$ & Regular periodicity & None & $2.0 \pm 0.29$ & $99 \cdot 0 \pm 7 \cdot 13$ \\
\hline 3 & $\begin{array}{l}\text { MBH (horizontally hatched } \\
\text { area-Text-figs } 2 \text { and } 4 \text { ) }\end{array}$ & None & None & $<0.5$ & - \\
\hline 6 & None & $\begin{array}{l}\text { 17-18-day intervals, } \\
\text { ended between December } \\
\text { and February }\end{array}$ & None & $1.9 \pm 0.18$ & $84 \cdot 3 \pm 8 \cdot 36$ \\
\hline
\end{tabular}

In 6 animals, in which lesions destroyed bilaterally nearly the whole SCN area (see Text-figs 2 and 3a), physiological oestrous cycles were observed with regular periodicity and ovulations during the whole breeding season. The basal plasma LH levels and the preovulatory LH peaks in these ewes were within the normal range shown by the control intact animals. In the nonbreeding season 4 out of the 6 ewes continued to ovulate regularly while 2 became anoestrous.

Four ewes, in which lesions destroyed bilaterally a significant portion of the SCN and the injury extended more caudally (see Text-fig. 2), experienced oestrous cycles with irregular dioestrous periods (24-31 days) during the breeding season. The basal plasma LH concentrations and preovulatory LH peaks were similar to those in the control animals. In the nonbreeding season all 4 continued to cycle irregularly. Three other ewes, with lesions placed more laterally and above SCN area (see Text-figs 2 and $3 \mathrm{~b}$ ), showed regular oestrous cycles throughout the whole breeding period but none after January. The animals in which lesions were placed in the ventro-medial infundibular region (Text-fig. 4) did not experience oestrous cycles during the observation period. These results are in accordance with our previous findings (Przekop \& Domański, 1970). In all 6 intact ewes oestrous cycles occurred regularly at 17-18day intervals and ovulations ceased between December and February (Table 1). 


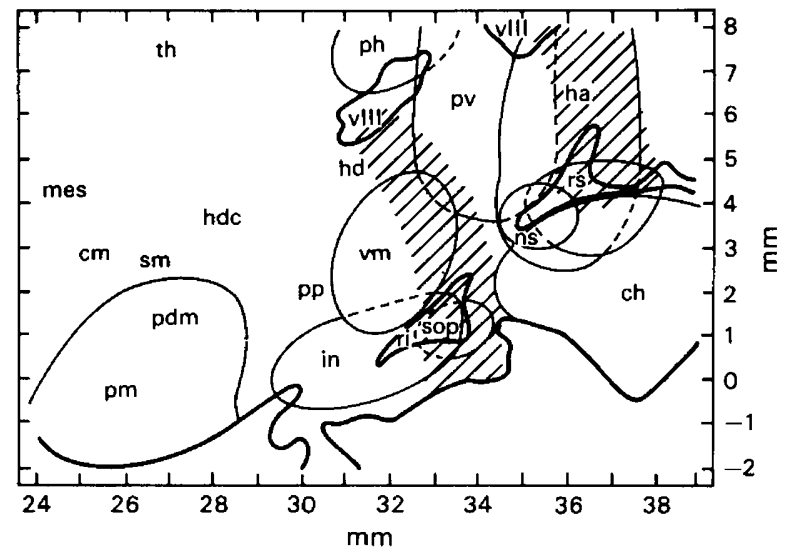

Text-fig. 1. Schematic localization of deafferentations in the sheep hypothalamus: sagittal section along plane 0.72 according to the stereotaxic atlas of Welento, Szteyn \& Milart (1969). Hatched areas denote location of the cuts in 10 animals at the midline level of the optic chiasma and in 11 animals caudally to the posterior border of the optic chiasma. Abbreviations for this and subsequent figures: ch, chiasma opticum; ci, capsula interna; cm, commissura supramamillaris; es, commissura anterior; $\mathbf{d m}$, nucleus dorsomedialis; $\mathbf{f x}$, fornix; ha, nucleus hypothalamicus anterior; hc, hypophysis cerebri; hd, area dorsalis hypothalami; hdc, area dorsocaudalis hypothalami; hl, area hypothalamica lateralis; in, nucleus infundibularis; mes, mesencephalon; np, nucleus hypothalamicus parvocellularis; ns, nucleus suprachiasmaticus; pdm, pars dorsomedialis nuclei mammilaris medialis; pf, nucleus perifornicalis; ph, parahorizontalis nuclei paraventricularis; pm, pars medialis nuclei mammilaris medialis; pp, nucleus periventricularis; pv, nucleus paraventricularis; ri, recessus infundibularis; rs, recessus supraopticus; sd, nucleus supraopticus diffusus; sm, nucleus supramammillaris; sop, pars posterior nuclei supraoptici; th, thalamus; to, tractus opticus; vm, nucleus ventromedialis; vIII, ventriculus tertius.

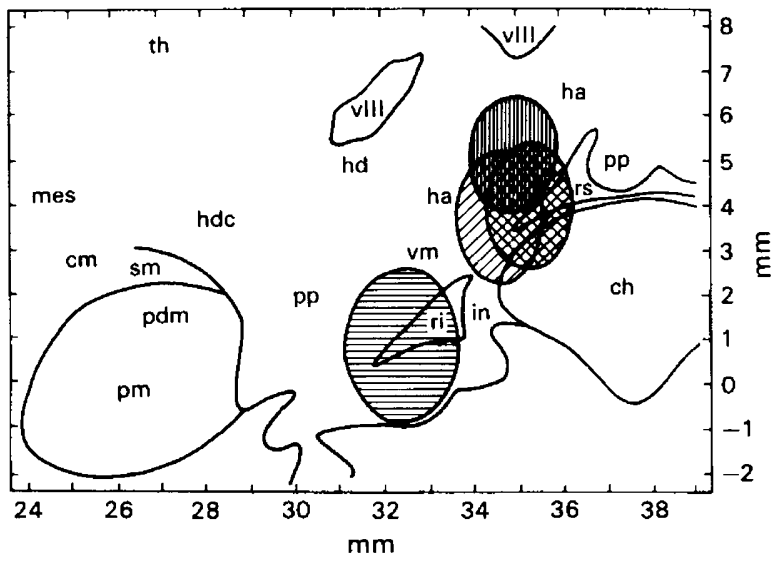

Text-fig. 2. Schematic localization of lesions in the sheep hypothalamus (sagittal section; hatched areas in the anterior hypothalamic area: $\mathrm{SCN}$ areas; $\mathrm{SCN}$ areas reaching more caudally; 面 areas above SCN; 目 site of lesion in the MBH. See Text-fig. 1 for abbreviations.

The data presented above clearly demonstrate an involvement of the preoptic area and SCN in the control of oestrous cycles in ewes. This involvement, however, is different from that known for the rat. In rats, damage to the SCN results in the elimination of ovulation because of disturbances in the phasic LH release. In sheep, damage to the SCN disturbed neither oestrous cycles nor the phasic LH release during breeding season, but did change the hypothalamic regulation of these processes during the non-breeding anoestrous season. These changes imply 
PLATE 1

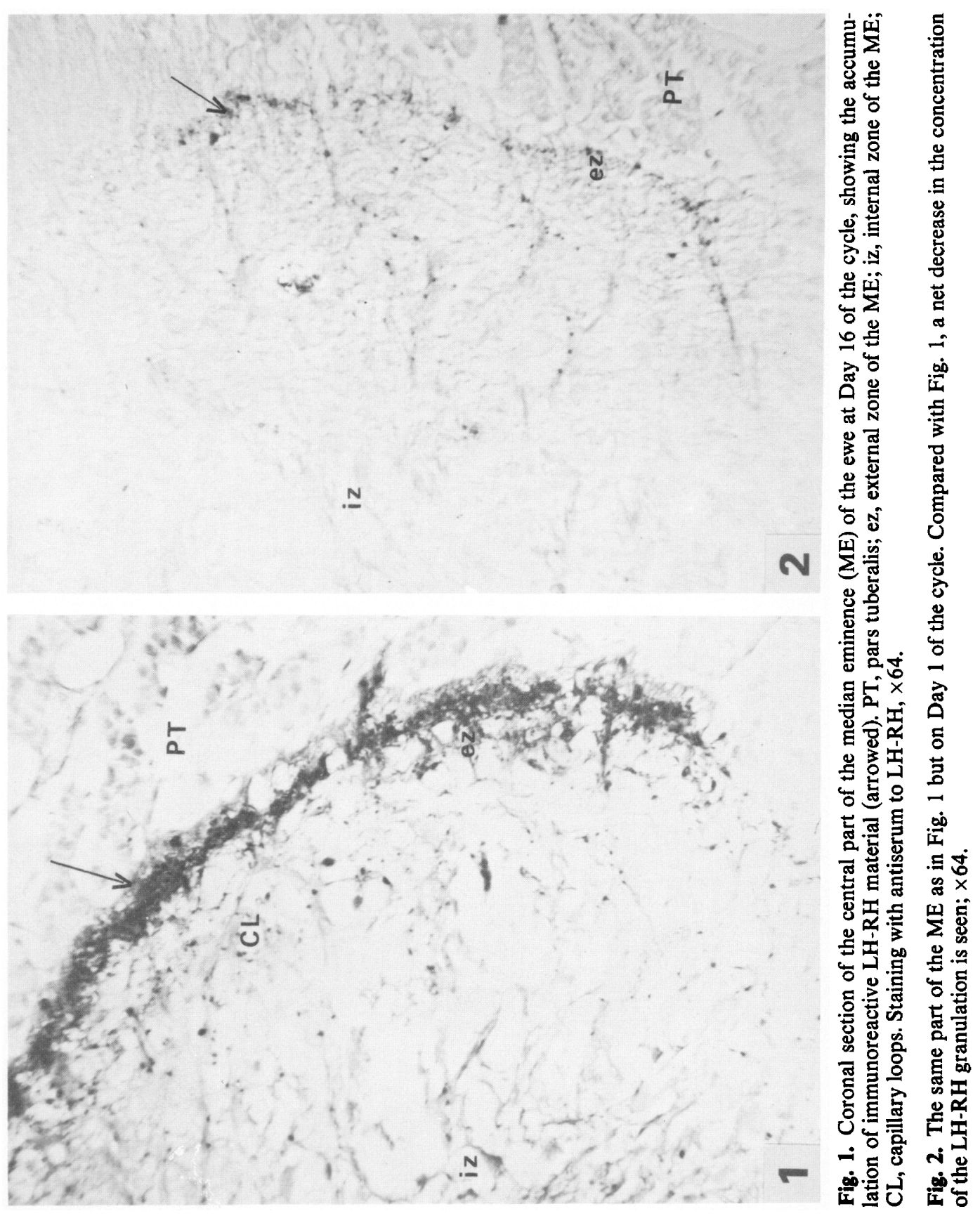

(Facing p. 496) 

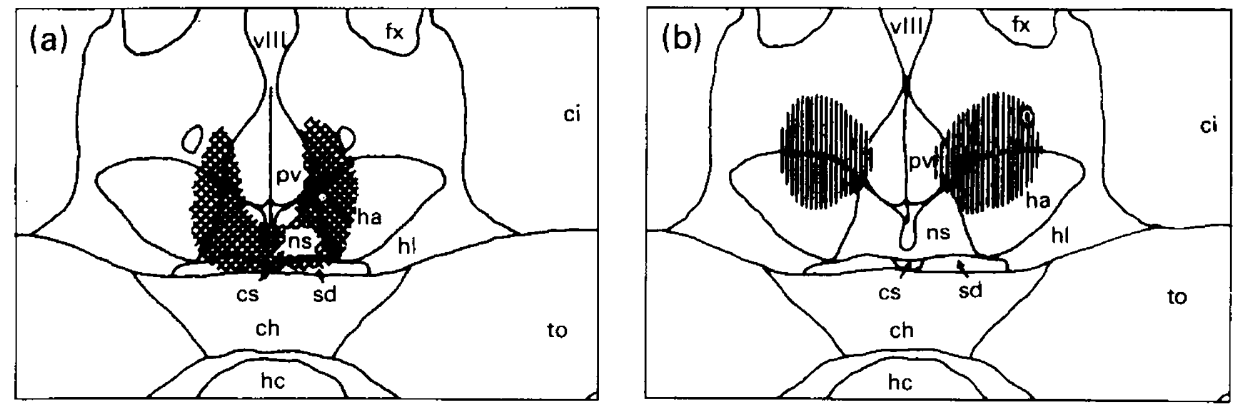

Text-fig. 3. Schematic localization of lesions in the sheep hypothalamus (frontal section) in (a) areas of the SCN, and (b) placed above the SCN. See Text-fig. 1 for abbreviations.

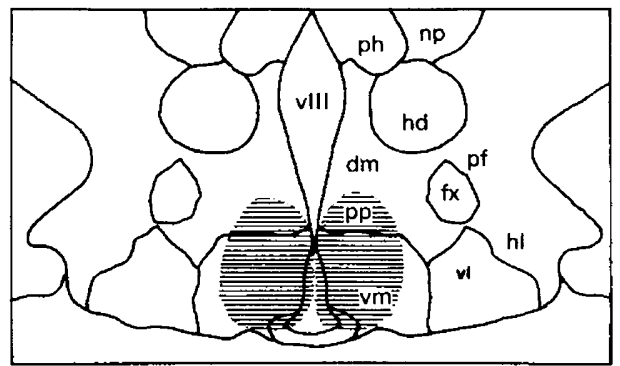

Text-fig. 4. Schematic localization of lesions in the sheep hypothalamus placed in the ventromedial-infundibular region (frontal section). See Text-fig. 1 for abbreviations.

that the SCN area either possesses itself the ability to exert an inhibitory action over the liberation of Gn-RHs during anoestrus or it receives only information concerning this action from higher formations of the CNS and transfers it to the lower levelof the hypothalamus. Our results demonstrate that lesions of the MPOA or anterior deafferentation of the SCN from the MPOA (Przekop \& Domański, 1970; Przekop, 1978), cause a similar extension of oestrous cycles over the quiescent sexual period, and tend therefore to support the second concept that the SCN receives and transfers this inhibitory action from the MPOA or even from extrahypothalamic formations.

When serotonin or melatonin were infused into the $\mathrm{MBH}$ area just before the critical period of the oestrous cycle in the ewes bearing lesions of MPOA and experiencing extended oestrous cycles during anoestrus, the release of $\mathrm{LH}$ and ovulation were blocked and delayed by 5-6 days or even until the next oestrous cycle (Domański, Przekop, Skubiszewski \& Wolińska, 1975). This experiment implies that the inhibitory pathway projecting from the MPOA is serotoninergic in nature.

The lack of disturbances of oestrous cycles during the breeding season in ewes after anterior deafferentation of the preoptic area or after lesions of the SCN indicates that the hypothalamic complex composed of the AHA and MBH retains the ability to produce Gn-RHs and regulate phasic LH release. However, the site in the hypothalamus where the impulse of this action is generated is unknown; it may be within the AHA-MBH complex or within some extrahypothalamic formations.

According to our earlier experiments (Przekop \& Domański, 1970) the process of phasic LH release in sheep seems to be associated with the AHA adjacent to the MPOA, since lesions to this area eliminated oestrous behaviour as well as oestrous cycles and ovulations. These effects of AHA lesions are in agreement with those following anterodorsal hypothalamic deafferentation performed behind the optic chiasma (see Text-fig. 1); this deafferentation eliminated 
oestrous cycles and phasic release of $\mathrm{LH}$, but did not suppress the tonic liberation of this hormone (Przekop, 1978). Blockage of oestrous cycles after antero-dorsal hypothalamic deafferentation performed caudally to the optic chiasma may be caused by elimination of AHA function or by cutting the afferent pathways sweeping down into the AHA-MBH from extrahypothalamic regions and transmitting the stimulatory impulses, e.g. of the noradrenergic system, which, according to the generally accepted view, is involved in the phasic liberation of Gn-RHs.

\section{Conclusions}

On the basis of the data presented above the following hypotheses and conclusions may be drawn. (1) Immunoreactive LH-RH material, participating in the control of gonadotrophin secretion in the rat as well as in the sheep, seems to be localized mainly in the median eminence but also in the AHA area. (2) The view on the tonic secretion of Gn-RHs and gonadotrophins is nearly unequivocal; all experimental results show that the $\mathrm{MBH}$ is involved in this process. (3) In the hypothalamic control of the phasic release of $\mathrm{Gn}-\mathrm{RH}$ s and concomitant gonadotrophin secretion, neurones located in the arcuate, ventro-medial and suprachiasmatic nuclei and anterior hypothalamic area are involved. According to electrophysiological and cytological investigations, these neurones project their axons to the ME (Dyer \& Cross, 1972; Cross, 1974; Yagi \& Sawaki, 1975a), are subjected to recurrent inhibition and excitation (Yagi \& Sawaki, 1975b), are influenced by projections from the preoptic region, amygdala and hippocampus (Yagi \& Sawaki, 1977) and are responsive to catecholamines (Moss, Kelly \& Riskind, 1975). (4) In the sheep, projections from the preoptic area seem to form an inhibitory pathway, leading through the SCN to $\mathrm{MBH}$, while the stimulatory projections probably sweep down from extrahypothalamic areas into the AHA-MBH complex, caudally to the optic chiasma. (5) According to generally accepted views, the serotoninergic system seems to exert an inhibitory action on the release of $\mathrm{Gn}-\mathrm{RH}$, whereas the noradrenergic system has a stimulatory effect.

\section{References}

Barraclough, C.A. (1973) Sex steroid regulation of reproductive neuroendocrine processes. In Handbook of Physiology: Section 7, Endocrinology, vol. 2, pp. 29-56. Ed. R. O. Greep. American Physiological Society, Washington, D.C.

Brown-Grant, K. \& Raisman, G. (1977) Abnormalities in reproductive function associated with the destruction of the suprachiasmatic nuclei in the female rat. Proc. R. Soc. Lond. B 198, 279-296.

Clemens, J.A., Smalstig, E.B. \& Sawyer, B.D. (1976) Studies on the role of the preoptic area in the control of reproductive function in the rat. Endocrinology 99 , $228-235$.

Cross, B.A. (1974) The neurosecretory impulse. In Neurosecretion-the Final Neuroendocrine Pathway, pp. 115-128. Eds F. Knowles \& L. Follrath. Springer, Berlin.

Domański, E., Przekop, F., Skubiszewski, B. \& Wolinska, E. (1975) The effect and site of action of indolamines on the hypothalamic centres involved in the control of LH-release and ovulation in sheep. Neuroendocrinology 17, 265-273.

Dyer, R.G. \& Cross, B.A. (1972) Antidromic identification of units in the preoptic and anterior hypo- thalamic area projecting directly to the ventromedial and arcuate nuclei. Brain Res. 43, 254-258.

Flerkó, B. (1970) Control of follicle stimulating hormone and luteinizing hormone secretion. In The Hypothalamus, pp. 351-363. Eds L. Martini, M. Motta \& F. Fraschini. Academic Press, New York.

Gray, G.D., Söderstein, P., Tallentire, D. \& Davidson, J.M. (1978) Effects of lesions in various structures of the suprachiasmatic-preoptic region on L.H regulation and sexual behaviour in female rats. Neuroendocrinology 25, 174-191.

Hayashi, S., Mennin, S.P. \& Gorski, R.A. (1974) Effect of hypothalamic deafferentation on luteinization of intra-splenic ovarian grafts in the ovariectomized rat. Neuroendocrinology 14, 321-332.

Moss, R.L., Kelly, R.M. \& Riskind, P. (1975) Tuberoinfundibular neurons: dopaminergic and norepinephrinergic. Brain Res. 29, 265-277.

Polkowska, J. \& Jutisz, M. (1979) Local changes in immunoreactive gonadotropin releasing hormone in the rat median eminence during the estrous cycle. Correlation with the pituitary luteinizing hormone. Neuroendocrinology 28, 281-288.

Przekop, F. \& Domański, E. (1970) Hypothalamic 
centres involved in the control of gonadotrophin secretion and ovulation in sheep. Acta physiol. polon. 21, 34-49.

Przekop, F. (1978) Effect of anterior deafferentation of the hypothalamus on the release of luteinizing hormone (LH) and reproduction function in sheep. Acta physiol. polon. 29, 393-407.

Sétáló, G., Vigh, S., Schally, A.V., Arimura, A. \& Flerko, B. (1976) Immunohistological study of the origin of LH-RH containing nerve fibers of the rat hypothalamus. Brain Res. 103, 597-602.

Stephan, E.K. \& Zucker, L. (1972) Circadian rhythms in drinking behavior and locomotor activity of rats are eliminated by hypothalamic lesions. Proc. natn. Acad. Sci., U.S.A. 69, 1583-1586.

Stetson, M.H. \& Watson-Whitmyre, M. (1976) Nucleus suprachiasmaticus: The biological clock in hamster. Science, N.Y. 190, 197-199.
Welento, J., Szteyn, S. \& Milart, Z. (1969) Observations on the stereotaxic configuration of the hypothalamus nuclei of the sheep. Anat. Anz. 124, 1-27.

Yagi, K. \& Sawaki, Y. (1975a) Recurrent inhibition and facilitation: demonstration in tubero-infundibular system and effects of strychnine and picrotoxin. Brain Res. 84, 155-159.

Yagi, K. \& Sawaki, Y. (1975b) Recurrent neural circuits in the tubero-infundibular system. In Brain-Endocrine Interaction. II. The Ventricular System in Neuroendocrine Mechanisms, pp. 257-269. Eds K. M. Knigge, D. E. Scott, H. Kobayashi \& S. Ishii. Karger, Basel.

Yagi, K. \& Sawaki, Y. (1977) Medial preoptic nucleus: Inhibition and facilitation of spontaneous activity following stimulation of the median eminence in female rats. Brain Res. 120, 342-346. 